\title{
Histomorphological Study of Placenta in Gestational Diabetes Mellitus
}

\author{
Estudio Histomorfológico de la Placenta en Diabetes Mellitus Gestacional
}

Naser A. El Sawy'; Mohammad Shahid Iqbal ${ }^{2} \&$ Abdullah G. Alkushi

EL SAWY, N. A.; IQBAL, M. S. \& ALKUSHI, A. G. Histomorphological study of placenta in gestational diabetes mellitus. Int. J. Morphol., 36(2):687-692, 2018.

SUMMARY: Evidence from the literature shows that well-controlled glucose levels during pregnancy are usually associated with normal placental morphology. The aim of this study was to identify the placental changes attributed to maternal hyperglycemia. A total of 20 placentae were selected for study from a tertiary care medical center in Makkah city, Saudi Arabia. Out of 20, 10 placentae were from patients diagnosed with GDM based on IADSPG criteria, and 10 placentae were from patients with normal pregnancies without GDM. The morphometric measurements were recorded. The mean weight of GDM placentae were more than the normal placentae. Upon histopathology, significant changes such as syncytial knots, cytotrophoblastic cell proliferation, fibrinoid necrosis, stromal fibrosis, and hyalinized villi were observed in GDM placentae. GDM produces significant morphological alterations in the placentae, which might affect the developing fetus.

KEY WORDS: Placenta; Chorangiosis; Trophoblast; Villi.

\section{INTRODUCCIÓN}

The placenta is a membranous vascular organ, which helps in fetomaternal exchanges (Saha et al., 2014).

Gestational diabetes mellitus (GDM) is defined as carbohydrate intolerance of variable severity with onset or first recognition during pregnancy. Gestational diabetes is important because more than half of women with GDM usually develop overt diabetes (Daskalakis et al., 2008).

In gestational diabetes, the delivery of large babies and large placentae is typical. Mothers with GDM also have high risk of hypertensive disorders, abortion, still birth, preterm labor, puerperal sepsis, etc. Infants born to mothers with GDM are at an increased risk of morbidity and mortality related to respiratory distress, growth abnormalities (large for gestational age, small for gestational age), hypoglycemia and congenital malformations (Saha et al.).

Since the placenta is positioned between maternal and fetal circulation, it is exposed to diabetes- associated endocrine and metabolic derangements of both the mother and fetus (Calderon et al., 2007).
Gestational diabetes mellitus has been known to raise the risk for large gestational age fetus as the maternal glucose crosses the placenta and stimulates fetal insulin secretion, which acts as the growth factor (Benhalima et al., 2015).

There has been a lack of uniformity in the approach to screening and diagnosis of GDM. There is a strong variability that exists internationally in the screening, diagnosis and management of women with GDM (Benhalima et al.).

As per the American Diabetes Association, GDM occurs when 2 abnormal values are observed in the $75 \mathrm{~g}$ oral glucose tolerance test (Calderon et al.).

The ADA has adopted the IADPSG recommendation since December 2010. The International Association of Diabetes and Pregnancy Study Groups (IADPSG) developed a new consensus that recommends screening for overt diabetes early in pregnancy and for a universal screening with the $2 \mathrm{~h} 75 \mathrm{~g}$ oral glucose tolerance test during 24-28 weeks of gestation (Benhalima et al.).

\footnotetext{
${ }^{1}$ Department of Anatomy, Faculty of Medicine, Zagazig University, Zagazig, Egypt.

${ }^{2}$ Department of Laboratory Medicine, College of Applied Medical Sciences, Umm al Qura University, Saudi Arabia.

${ }^{3}$ Department of Anatomy, Faculty of Medicine, Umm-AlQura University, Saudi Arabia.
} 
The IADPSG criteria explains that just 1 abnormal value is sufficient to diagnose GDM. GDM is considered if $\geq 92 \mathrm{mg} / \mathrm{dl}$ is detected after 1 hour of $2-\mathrm{h} 75 \mathrm{~g} / \mathrm{OGTT}, \geq 180$ $\mathrm{mg}$ of glucose is detected after 2 hours, or $\geq 153 \mathrm{mg}$ of glucose is detected after 3 hours (Benhalima et al.).

Thorough examination of the placenta after birth reveal changes that occur due to GDM. Some of the changes described in the literature are changes such as endarteritis, chorangiosis, edema, hypo and hyper ramifications of the terminal villi, infarction, fibrotic villi and villous basement membrane changes in diabetic placentae (Calderon et al.).

The extent to which maternal glycemic control contributes to placental abnormalities remains unclear. Evidence from the literature shows that well controlled glucose levels during pregnancy are generally associated with normal placentae under light microscopy (Huynh et al., 2015).

The aim of our study was to use light microscopy to observe the morphological changes in placentae of women with GDM and to compare the histological findings with placentae in normal women without GDM.

\section{MATERIAL AND METHOD}

A total of 20 placentae were selected for the study. Ten placentae were from women who were diagnosed with GDM based on IADSPG criteria, and 10 placentae were from women with normal pregnancies without GDM. All the cases were singleton term deliveries from a tertiary care hospital, Holy Makkah City, Saudi Arabia. Placental specimen examination and grossing of placentae were performed according to a standard gross template. At least 3 representative sections of placenta were sampled for histology. The gross parameters examined and recorded included placental weight, cord length and cord insertion site. For the histopathological study, one whole thickness placental section from the central part of the placenta was taken and fixed in $10 \%$ formal saline for 3 days, and later processed like routine specimens for histology; 4-5 $\mu \mathrm{m}$ thick sections were stained with Hematoxylin and Eosin and examined under a light microscope at various magnifications.

\section{RESULTS}

The following morphometric observations were made after examining the placentae from both groups. The mean weight of placentae in the normal group was $417 \mathrm{~g}$, and that of placentae in the GDM group was $571 \mathrm{~g}$. Similarly, there was a significant difference in various parameters $(\mathrm{p}<001)$ such as placental area, placental diameter, placental thickness and circumference between the two groups (Tables I and Figs. 1, 2, 3).

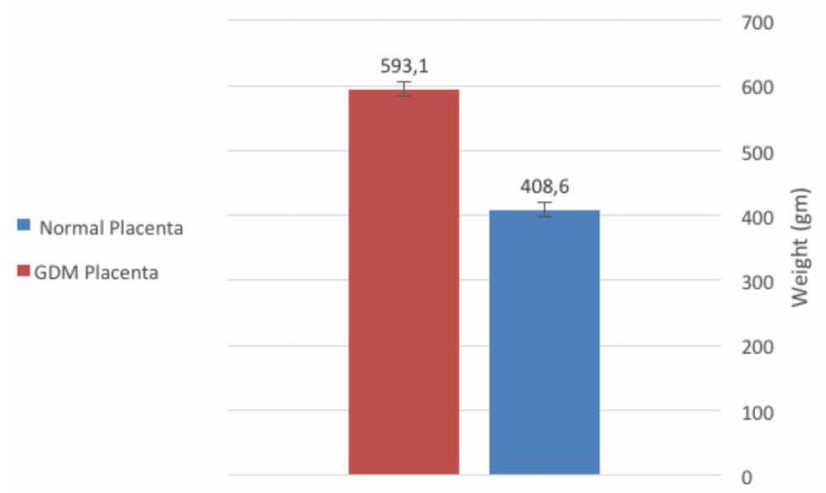

Fig. 1. It shows the difference in thickness, Diameter and circumference $(\mathrm{cm})$ in normal and GDM placenta.

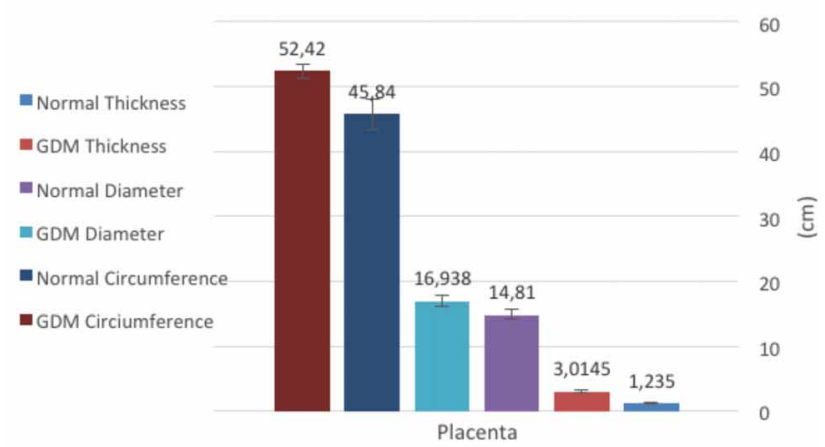

Fig. 2. It shows the difference in weight (gm) in normal and GDM placenta.

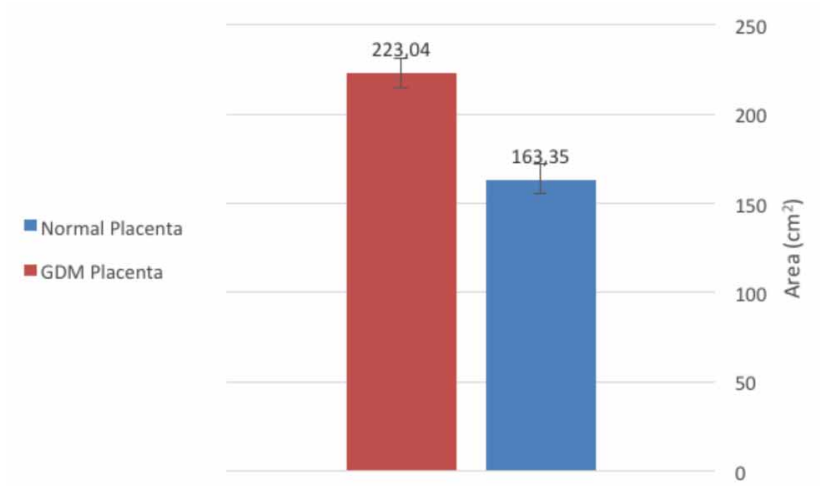

Fig. 3. It shows the difference in area $\left(\mathrm{cm}^{2}\right)$ in normal and GDM placenta.

The site of cord insertion among the normal placentae and the GDM placentae is mentioned in Table II. There was variability of cord insertion sites. 
Table I. Morphometric finding of normal placentae with GDM.

\begin{tabular}{lccc}
\hline & Normal Placenta & GDM Placenta & P value \\
\hline Weight $(\mathrm{gm})$ & $408.6 \pm 10$ & $593.1 \pm 9.6$ & $<0.001$ \\
Area $\left(\mathrm{cm}^{2}\right)$ & $163.35 \pm 7.96$ & $223.04 \pm 5.68$ & $<0.001$ \\
Thickness $(\mathrm{cm})$ & $1.2350 \pm 0.0650$ & $3.0145 \pm 0.0735$ & $<0.001$ \\
Diameter $(\mathrm{cm})$ & $14.810 \pm 0.306$ & $16.938 \pm 0.250$ & $<0.001$ \\
Circumference $(\mathrm{cm})$ & $45.84 \pm 1$ & $52.42 \pm 0.78$ & $<0.001$ \\
\hline
\end{tabular}
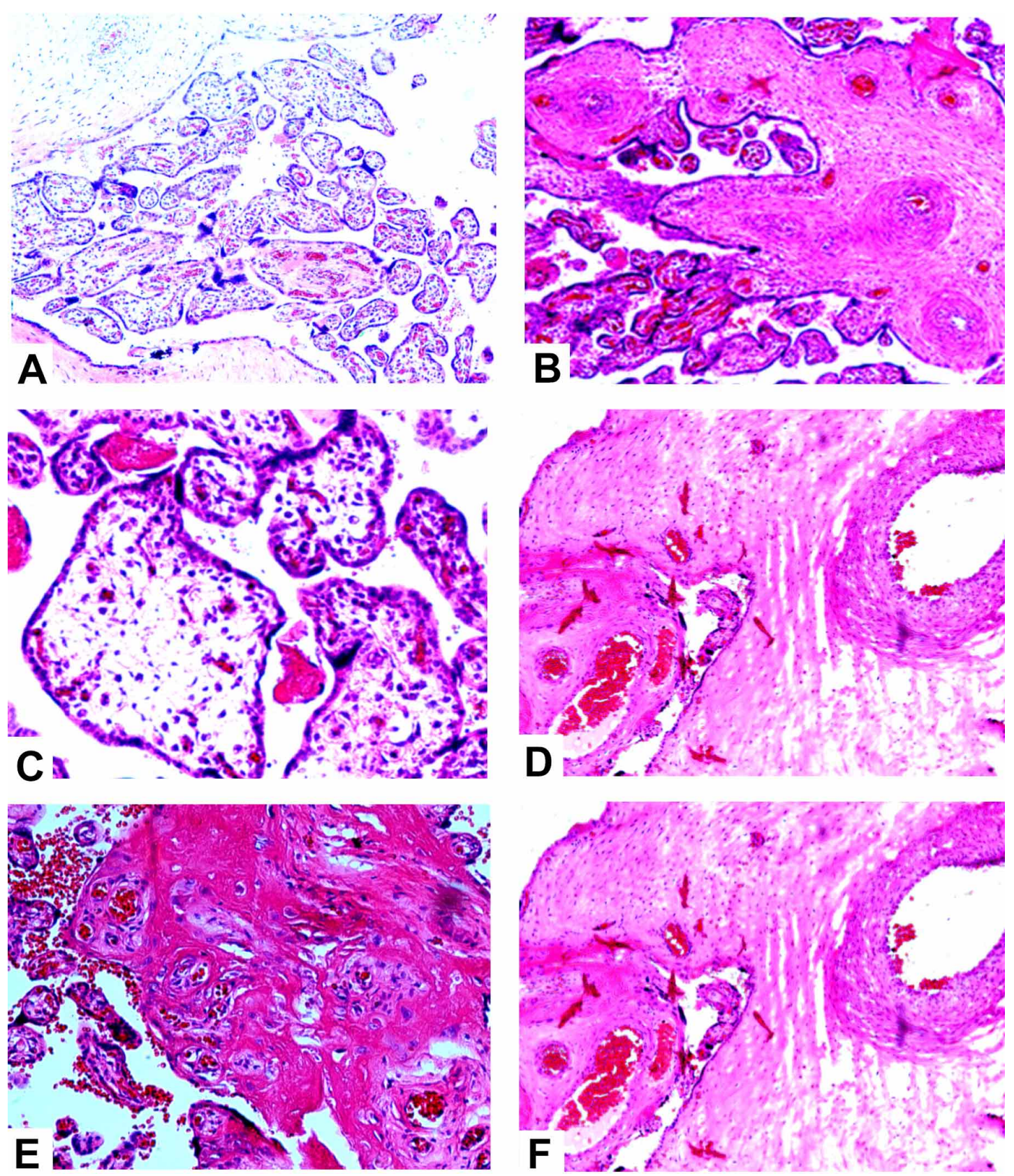

Fig. 4. A. Normal placenta showing villi of different sizes separated by intervillous spaces of different sizes. The villi showed cells of trophoblast and contained peripheral thin walled blood vessels and others are patent x20; B. Placenta from GDM showing stromal fibrosis X20; C. Placenta with GDM showing villous edema X20.; D. GDM placenta showing Fibrinoid Thrombi X20.; E. GDM placenta showing Fibrinoid necrosis X20.; F. GDM placenta showing Thickened blood vessels uncontrolled X20. 
In normal placentae, the villi were of different sizes varying from small to large in diameter. The large villi represented the fully mature villi, while the smaller ones were not fully mature. The villi were lined by trophoblasts and had many blood vessels. The blood vessels were peripherally placed in villi and some of the blood vessels were patent while others contained fibrinoid thrombi. The trophoblasts contained aggregates of nuclei, termed syncytial knots. The intervillous spaces were varying in width, but mostly small in size. There were small aggregates of fibrinoid material between the villi (Fig. 4A).

The placentae of women with GDM showed an increased number of villi. The blood vessels in the villi were significantly increased in number. Most of the villi had larger blood vessels in the center, while other small vessels were peripheral. The walls of the blood vessels were thicker than the normal placentae. There were few syncytial knots in the villi. In the GDM placentae, the significant changes observed were syncytial knots, cytotrophoblastic cell proliferation, fibrinoid necrosis, stromal fibrosis, and hyalinized areas with villi (Fig. 4B). The intervillous spaces were of different sizes, but some of the spaces were wider than in normal placentae due to intervillous edema with increased content of fibrinoid material (Fig. 4C). Occasional areas of calcification were also observed. Most of the peripheral blood vessels contained fibrinoid thrombi, so that most of the villi were shown to contain fibrinoid thrombi (Fig. 4D). Occasional areas of fibrinoid necrosis were also observed (Fig. 4E). Most of the peripheral blood vessels thickened (Fig. 4F). These changes were observed to a minimal extent in normal placentae but also more in diabetic placentae.

Table II. Umbilical cord insertion site.

\begin{tabular}{lccc}
\hline & \multicolumn{3}{c}{ Site of cord insertion } \\
& Eccentric & Central & Marginal \\
\hline Normal group placentae $(\mathrm{N}=10)$ & 04 & 02 & 04 \\
GDM group placentae $(\mathrm{N}=10)$ & 06 & 02 & 02 \\
\hline
\end{tabular}

\section{DISCUSSION}

In normal placentae, the villi contained few blood vessels that were mostly peripherally placed. The walls of these blood vessels were thin.

The villous blood vessels contain the fetal blood, while the intervillous spaces contain the maternal blood. Therefore, in normal placentae, the fetal and maternal blood are separated by the layers of trophoblasts and the thin wall of the blood vessels. This is called the placental barrier that separates the fetal and maternal blood (Laurini et al., 1987).

Therefore, in normal placentae, the thin placental barrier allows for easy transfer of oxygen nutrients between the fetal and maternal blood (Laurini et al.).

In diabetic patients, there was an increase in the number of the blood vessels per villous. This is due to increased neoangiogenesis in the diabetic patients. These blood vessels are immature and some of them contained fibrinoid thrombi, but all the vessels had thicker walls. In the diabetic placentae, some of the villous blood vessels were located in the central areas of the villi. Consequently, the thickness of the placental barrier was increased in the diabetic placentae. Additionally, the peripheral thick-walled vessels showed the same thick placental barrier leading to decreased oxygen and nutrient transfer from the mother to the fetus, due to the increased distance between the maternal blood in the intervillous spaces and the fetal blood in the blood vessels of the villi (Teasdale, 1981).

It was reported that vascular endothelial growth factor (VEGF), a potent stimulator of angiogenesis, has been implicated as one of the possible causes of angiogenesis in diabetic placenta, due to placental VEGF overexpression (Cohen et al., 2001; Grosfeld et al., 2002; Grissa et al., 2010).

The production of VEGF is enhanced by hypoxia resulting from poor oxygen transfer from the mother to the embryo. This is augmented by the AGEs (advanced glycation end products) released due to hypoxia and oxidative stress (Grosfeld et al.).

It was stated that angiotensin II stimulates the production of VEGF, and it has been shown that inhibiting angiotensin-converting enzyme (ACE) reduces VEGF overexpression in experimental diabetes. Thus, ACE inhibitor drugs may affect diminished neoangiogenesis in diabetic pregnancies (Fox, 1969).

The involvement of VEGF in diabetic microangiopathy may not be restricted to the placenta. VEGF and its receptor are expressed in human kidney and retina, 
where it is involved in the pathogenesis of ocular angiogenesis, proliferative diabetic retinopathy and the development of macular edema (Duh \& Aiello, 1999).

The stroma and the cells of the trophoblasts of the villi were edematous due to the leak from the large number of immature blood vessels in the villi (Teasdale; Duh \& Aiello).

Again, VEGF may also be involved in the pathogenesis of intravillous edema due to the large number of new blood vessels in the villi with their thrombus content (Duh \& Aiello).

Additionally, the intervillous spaces were edematous as evidenced by the increased width of some of the intervillous spaces and the content of fibrinoid thrombi in the diabetic placentae. This may be due to the increased permeability of these new immature blood vessels (Teasdale).

Thus, it could be postulated that the production of new immature blood vessels in the diabetic villi, as shown in the present study, could enhance the accumulation of intravillous edema and the peri-villous edema in the intervillous spaces (Teasdale).

The immature blood vessels were recorded to be more permeable to substances, including water and albumin (Grosfeld et al.). Edema will decrease the blood flow in the villous blood vessels and lead to ischemia of the villi and interfere with the transfer of oxygen and nutrients from the maternal blood to the fetal blood. It also enhances more production of VEGF in the placental tissues (Duh \& Aiello; Cohen et al.).

The involvement of VEGF in diabetic microangiopathy is also claimed to be involved in macular edema in the eye and glomerular edema in the kidney (Duh \& Aiello; Gilbert et al., 2000).

The increased thickness of the placental barrier together with the villi ischemia due to intravillous and perivillous edema in this study may decrease the nutrient and oxygen delivery to the fetuses of diabetic mothers. This might explain the increased incidence of fetal abnormalities delivered by some of the diabetic mothers (Feig et al., 2008).

\section{CONCLUSION}

Diabetes mellitus increases the vascularity of the chorionic villi and increases the thickness of the placental barrier leading to hypoxia, which also increases edema inside and outside the villi. The villi become thick with edema and the accumulation of fibrinoid materials in the villous blood vessels.

EL SAWY, N. A.; IQBAL, M. S. \& ALKUSHI, A. G. Estudio histomorfológico de la placenta en diabetes mellitus gestacional. Int. J. Morphol., 36(2):687-692, 2018.

RESUMEN: La evidencia de la literatura muestra que niveles de glucosa bien controlados durante el embarazo generalmente se asocian con una morfología placentaria normal. El objetivo de este estudio fue identificar los cambios placentarios atribuidos a la hiperglucemia materna. Un total de 20 placentas fueron seleccionadas para un estudio en un centro médico de atención terciaria en la ciudad de La Meca, Arabia Saudita. De 20 placentas, 10 de estas fueron de pacientes diagnosticadas con diabetes mellitus gestacional (DMG) según los criterios de IADSPG, y 10 placentas fueron de pacientes con embarazos normales sin DMG. Las mediciones morfométricas fueron registradas. El peso medio de las placentas GDM fue mayor que la placenta normal. Tras la histopatología, se observaron cambios significativos tales como nudos sincitiales, proliferación celular citotrofoblástica, necrosis fibrinoide, fibrosis estromal y vellosidades hialinizadas en placenta con DMG. La DMG produce alteraciones morfológicas significativas en las placentas, que pueden afectar al desarrollo del feto.

PALABRAS CLAVE: Placenta; Corangiosis; Trofoblasto; Vellosidades.

\section{REFERENCES}

Benhalima, K.; Devlieger, R. \& Van Assche, A. Screening and management of gestational diabetes. Best Pract. Res. Clin. Obstet. Gynaecol., 29(3):339-49, 2015.

Calderon, I. M.; Damasceno, D. C.; Amorin, R. L.; Costa, R. A.; Brasil, M. A. \& Rudge, M. V. Morphometric study of placental villi and vessels in women with mild hyperglycemia or gestational or overt diabetes. Diabetes Res. Clin. Pract., 78(1):65-71, 2007.

Cohen, B.; Barkan, D.; Levy, Y.; Goldberg, I.; Fridman, E.; Kopolovic, J. \& Rubinstein, M. Leptin induces angiopoietin-2 expression in adipose tissues. J. Biol. Chem., 276(11):7697-700, 2001.

Daskalakis, G.; Marinopoulos, S.; Krielesi, V.; Papapanagiotou, A.; Papantoniou, N.; Mesogitis, S. \& Antsaklis, A. Placental pathology in women with gestational diabetes. Acta Obstet. Gynecol. Scand., 87(4):403-7, 2008.

Duh, E. \& Aiello, L. P. Vascular endothelial growth factor and diabetes: the agonist versus antagonist paradox. Diabetes, 48(10):1899-906, 1999.

Feig, D. S.; Zinman, B.; Wang, X. \& Hux, J. E. Risk of development of diabetes mellitus after diagnosis of gestational diabetes. C. M. A. J., 179(3):229-34, 2008.

Fox, H. Pathology of the placenta in maternal diabetes mellitus. Obstet. Gynecol., 34(6):792-8, 1969.

Gilbert, R. E.; Kelly, D. J.; Cox, A. J.; Wilkinson-Berka, J. L.; Rumble, J. R.; Osicka, T.; Panagiotopoulos, S.; Lee, V.; Hendrich, E. C.; Jerums, G. \& Cooper, M. E. Angiotensin converting enzyme inhibition reduces retinal overexpression of vascular endothelial growth factor and 
hyperpermeability in experimental diabetes. Diabetologia, 43(11):1360$7,2000$.

Grissa, O.; Yessoufou, A.; Mrisak, I.; Hichami, A.; Amoussou-Guenou, D.; Grissa, A.; Djrolo, F.; Moutairou, K.; Miled, A.; Khairi, H.; Zaouali, M.; Bougmiza, I.; Zbidi, A.; Tabka, Z. \& Khan, N. A. Growth factor concentrations and their placental mRNA expression are modulated in gestational diabetes mellitus: possible interactions with macrosomia. B. M. C. Pregnancy Childbirth, 10:7, 2010.

Grosfeld, A.; Zilberfarb, V.; Turban, S.; André, J.; Guerre-Millo, M. \& Issad, T. Hypoxia increases leptin expression in human PAZ6 adipose cells. Diabetologia, 45(4):527-30, 2002.

Huynh, J.; Dawson, D.; Roberts, D. \& Bentley-Lewis, R. A systematic review of placental pathology in maternal diabetes mellitus. Placenta, 36(2):101-14, 2015

Laurini, R. N.; Visser, G. H.; van Ballegooie, E. \& Schoots, C. J. Morphological findings in placentae of insulin-dependent diabetic patients treated with continuous subcutaneous insulin infusion (CSII). Placenta, 8(2):153-65, 1987.

Saha, S.; Biswas, S.; Mitra, D.; Adhikari, A. \& Saha, C. Histologic and morphometric study of human placenta in gestational diabetes mellitus. Ital. J. Anat. Embryol., 119(1):1-9, 2014.

Teasdale, F. Histomorphometry of the placenta of the diabetic women: class A diabetes mellitus. Placenta, 2(3):241-51, 1981.
Corresponding Author:

Abdullah G. Al-Kushi

Department of Anatomy

Faculty of Medicine

Umm Al-Qura University

P.O. Box: 57039

Azeezeeyah, Makkah

SAUDI ARABIA

E-mail: dr.alkushi@gmail.com

Received: 10-01-2018

Accepted: 22-02-2018 